American J. of Engineering and Applied Sciences 5 (1): 93-97, 2012

ISSN 1941-7020

(C) 2014 Z. Asry et al., This open access article is distributed under a Creative Commons Attribution

(CC-BY) 3.0 license

\title{
Geoelectrical Resistivity Imaging and Refraction Seismic Investigations at Sg.Udang, Melaka
}

\author{
Zeinab Asry, Abdul Rahim Samsudin, \\ Wan Zuhairi Yaacob and Jasni Yaakub \\ School of Environmental and Natural Resource Science, \\ Faculty of Science and Technology, Universiti Kebangsaan, Malaysia
}

\begin{abstract}
Problem statement: A Reconnaissance geophysical survey of an area near Sg.Udang, Melaka was conducted using geoelectrical resistivity and seismic refraction methods. The main objective of this study is to determine the depth of bedrock in the study area. The resistivity imaging measurement employing Wenner electrode configuration was carried out using an ABEM SAS 1000 terrameter and electrode selector system ES464. Electrodes were arranged in a straight line with constant spacing and connected to a multicore cable. The refraction seismic was conducted using 24 channel ABEM Mark6 signal enhancement seismograph with $5 \mathrm{~m}$ geophone spacing. The resistivity layer is associated with the residual soil with thickness of about $0.5-3 \mathrm{~m}$. The high velocity layer is an average depth of about $9.4 \mathrm{~m}$. The intermediate velocity zone is associated with weathered schist with thickness of about $2.5 \mathrm{~m}$. The low velocity zone is with thickness of about $6 \mathrm{~m}$. The thickness of residual soil obtained by seismic refraction survey appears to agree very well with the borehole data. Resistivity and the seismic refraction data have been successfully used to determine the thickness of residual soil layer and depth of bedrock. Approach: In this survey, electrodes were arranged in a straight line with constant spacing and connected to a multicore cable. The refraction seismic was conducted using 24 channel ABEM Mark6 signal enhancement seismograph with $5 \mathrm{~m}$ geophone spacing. The seismic data have been interpreted using SeisOpt@2D which automatically produced 2-D seismic velocity sections of the subsurface. Results: The resistivity results showed that the subsurface layers are associated with variable resistivity $(296-2600 \Omega$. m). The resistivity layer is associated with the residual soil with thickness of about 0.5-3 m. The interpreted 2-D seismic sections showed three different velocity layers. The high velocity layer $\left(1600-2000 \mathrm{~m} \mathrm{sec}^{-1}\right)$ is interpreted to be associated with bedrock at an average depth of about $9.4 \mathrm{~m}$. The intermediate velocity zone (1000-1600 m sec $\left.\mathrm{s}^{-1}\right)$ is associated with weathered schist with thickness of about $2.5 \mathrm{~m}$. The low velocity zone (450-900 m $\mathrm{sec}^{-1}$ ) corresponds to clayey silt of residual soil with thickness of about $6 \mathrm{~m}$. Borehole data indicate that the depth of bedrock is about $10 \mathrm{~m}$ which appears to be in good agreement with that of seismic results. Conclusion: Interpretation of the resistivity and the seismic refraction data have been successfully used to determine the thickness of residual soil layer and depth of bedrock in the study area. The thickness of residual soil obtained by seismic refraction survey appears to agree very well with the borehole data.
\end{abstract}

Key words: Geophysical survey, resistivity imaging, seismic refraction, depth of bedrock

\section{INTRODUCTION}

Over the last several decades, geophysical methods have been very famous and successfully used to get information below the earth surface. The geophysical study described in this study is based mainly on geoelectrical and seismic surveys. The goal of a geoelectrical resistivity surveys is to determine subsurface resistivity distributions by taking measurements of the apparent resistivity on the ground surface. Geoelectrical resistivity surveys have become an important tool in environmental and engineering applications. The electrical resistivity is complentary in many ways although this method measures resistivity of the subsurface. In the seismic refraction method, energy is introduced into the ground by striking steel plate at the ground surface with a hammer. The seismic energy generated is detected by a line of 24 equally spaced geophones which are placed in the ground and produce a small voltage in response to earth vibration.

Corresponding Author: Zeinab Asry, School of Environmental and Natural Resource Science, Faculty of Science and Technology, Universiti Kebangsaan, Malaysia 


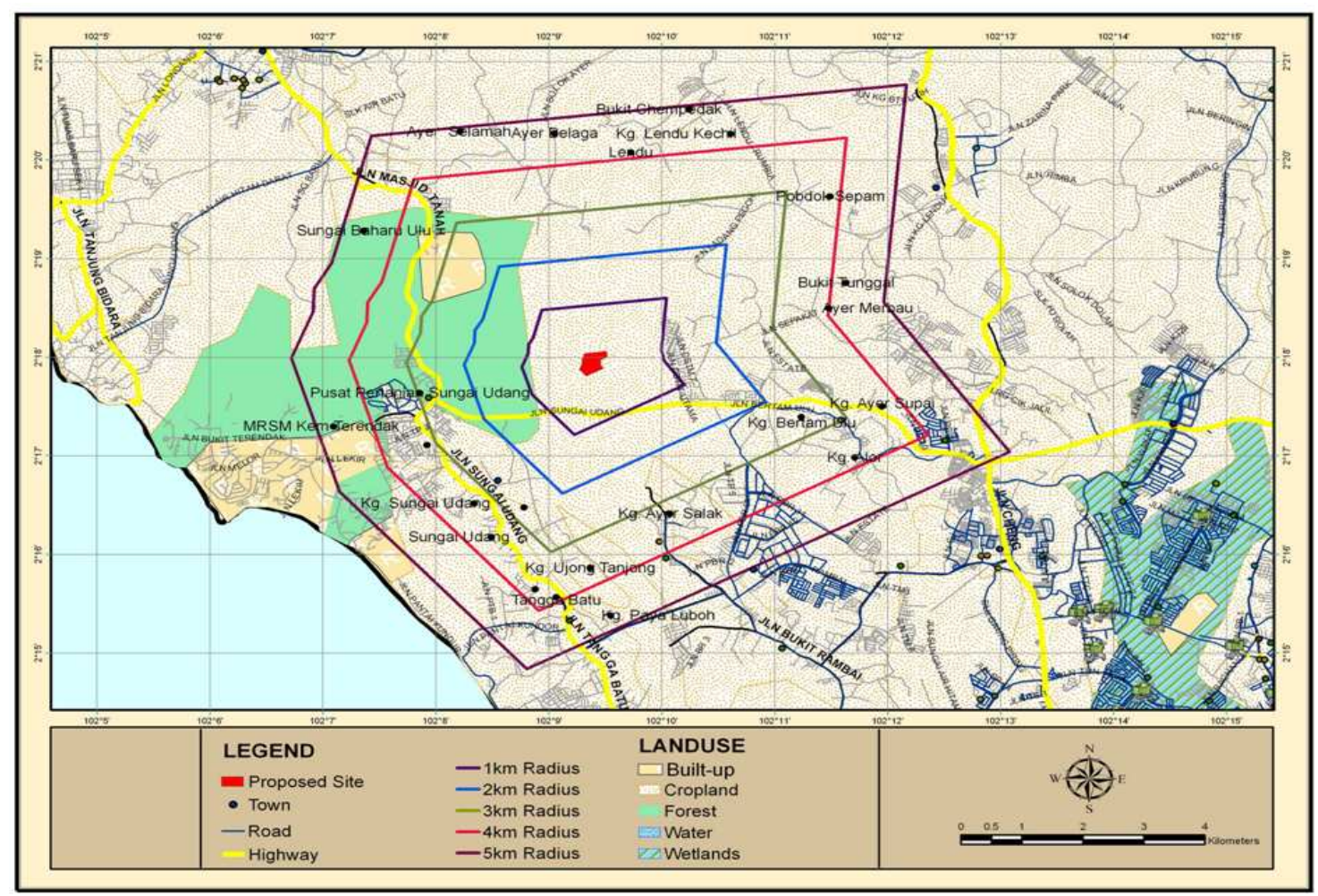

Fig. 1: Location map of study area

An integrated geophysical method which includes electrical resistivity and seismic refraction techniques were carried out to study the depth of bedrock at Sg.Udang landfill site in Melaka Fig. 1. The survey area is located about $15 \mathrm{~km}$ from Melaka city center and about $3 \mathrm{~km}$ from $\mathrm{Sg}$. Udang town. It is bounded by latitudes $\mathrm{N} 2{ }^{\circ} \mathrm{C} 18.55^{\prime}$ and $\quad \mathrm{N} 2{ }^{\circ} \mathrm{C} \quad 18.78^{\prime}$ longitudes $\mathrm{E} 102^{\circ} \mathrm{C} 9.359^{\prime}$ and $\mathrm{E} 102^{\circ} \mathrm{C} 9.448^{\prime}$. The existing site is currently surrounded by oil-palm and rubber estate. It covers an area of about 32 acres with undulating topography. The lowest topography is located in southwestern part of the site and a relatively high ground is occupying the northeastern region of the study area. The surface soil material is mainly clayey silt. This material is derived from the in-situ weathering of the schist, which forms the bedrock of the survey area. Examination of a moderately to highly weathered cut slope at the entry road to the site shows that the schist is highly fractured.

\section{MATHERIALS AND METHODS}

Resistivity survey was conducted using ABEM SAS 1000 Terrameter and Lund electrode selector system ES464.

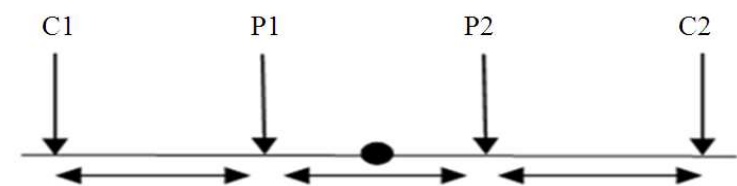

Fig. 2: Electrode arrangement for Wenner array configuration

For data collection, 41 electrodes were arranged in a straight line with constant spacing and connected to a multicore cable. The electrode selector system will automatically select the relevant four active electrodes for each measurement of resistivity data. The data were processed by using inversion software RES2DINV (Loke and Barker, 1995). Basically, the data from these surveys are commonly arranged and contoured in the form of a pseudo section which gives an appropriate picture of the subsurface resistivity (Loke et al., 2003). Two lines of 2-D electrical resistivity imaging were performed along profiles with its center located at borehole BH1. A Wenner electrode configuration Fig. 2 was used during the resistivity measurements with electrode spacing of 2 and $5 \mathrm{~m}$. The two outer current electrodes ( $\mathrm{C} 1$ and $\mathrm{C} 2$ ) supply the constant electric current (I). The inner electrodes (P1 and P2) measure 
the voltage difference. The apparent resistivity of the subsurface can be computed using the following formula. $\mathrm{P}=2 \pi \mathrm{aR}$ where $\mathrm{a}=$ electrode space and $\mathrm{R}=$ resistance $=$ resistance $(\mathrm{V} / \mathrm{I})($ Telford et al., 1990).

As a result of the developments in multi electrode resistivity equipment and data acquisition technique, the electrical resistivity imaging has become a standard tool in near-surface geophysical surveys (Griffiths and Barker, 1993; Barker, 1981). Seismic refraction method is based on the travel time measurements of the first arrivals, including direct, refracted and diffracted wave phases. The velocity contrast is one of the main parameters controlling the resolution of the method. The total length of the seismic line is $115 \mathrm{~m}$ and was coincident with electrical resistivity line along the same profile. The geophone cable is a multi-conductor cable with 24 connectors molded at intervals along the cable. Geophones have been placed with distance of either 2 or $5 \mathrm{~m}$. A 24 channel ABEM TERRALOC MARK III signal enchancement seismograph was employed for the seismic survey together with a $5.5 \mathrm{~kg}(12 \mathrm{Ib})$ sledge hammer as the energy source. A seven point energy source position (hammer point) configuration was employed for all seismic spreads, the energy source position being- 5, 2.5, 27.5, 57.5, 87.5, 112.5 and 120 $\mathrm{m}$. Geophones were spaced at $5 \mathrm{~m}$ intervals. The ABEM seismograph enable seismic records obtained to be stored which can subsequently be retrieved for data processing. The data were interpreted using SeisOpt@2D software.

\section{RESULTS}

Figure 3 and 4 show the results of a seismic refraction survey at borehole $1(\mathrm{BH} 1)$ for geophone spacing 2 and $5 \mathrm{~m}$ respectively. The results indicate that the seismic velocity of the layered material increases from 450-3000 m sec${ }^{-1}$ with maximum depth of penetration about $30 \mathrm{~m}$.

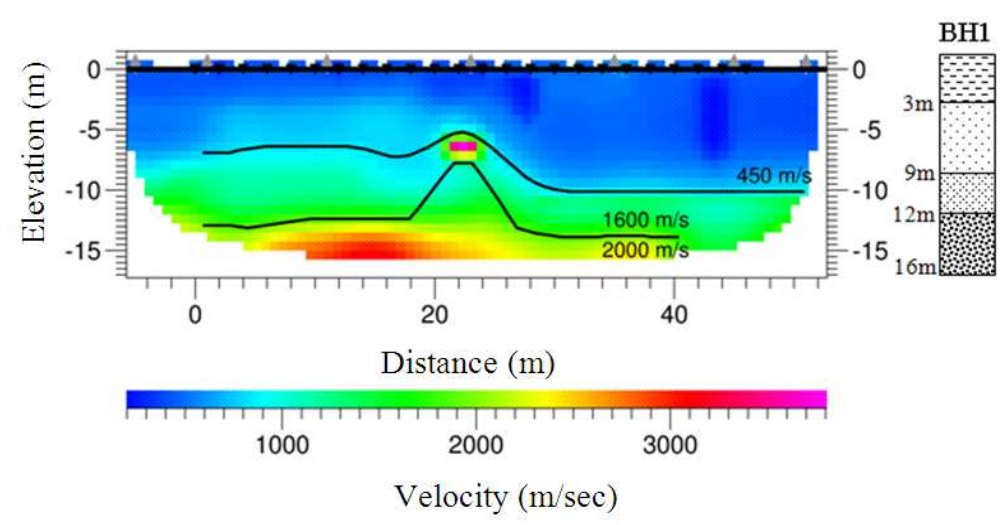

Fig. 3: The 2D profiles of the refraction seismic velocity for $2 \mathrm{~m}$ geophone spacing

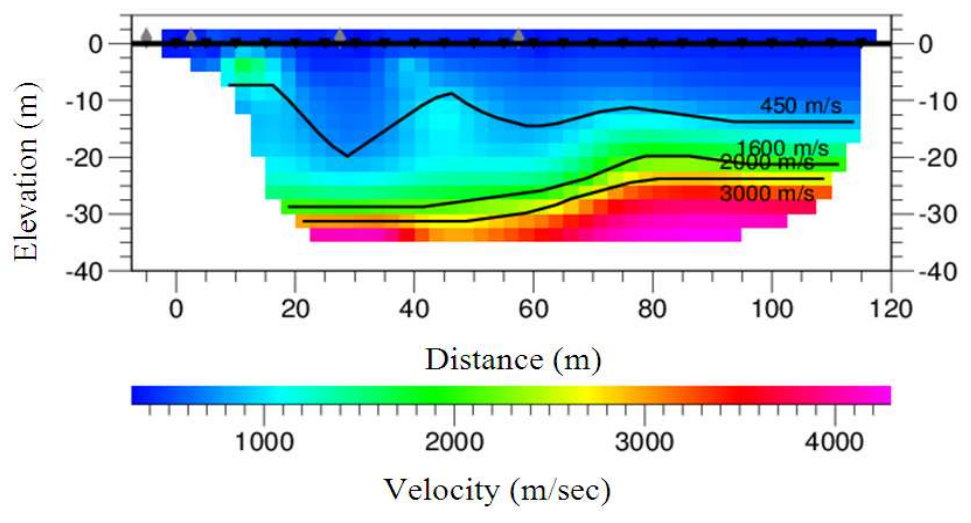

Fig. 4: The 2D profiles of the refraction seismic velocity for $5 \mathrm{~m}$ geophone spacing 


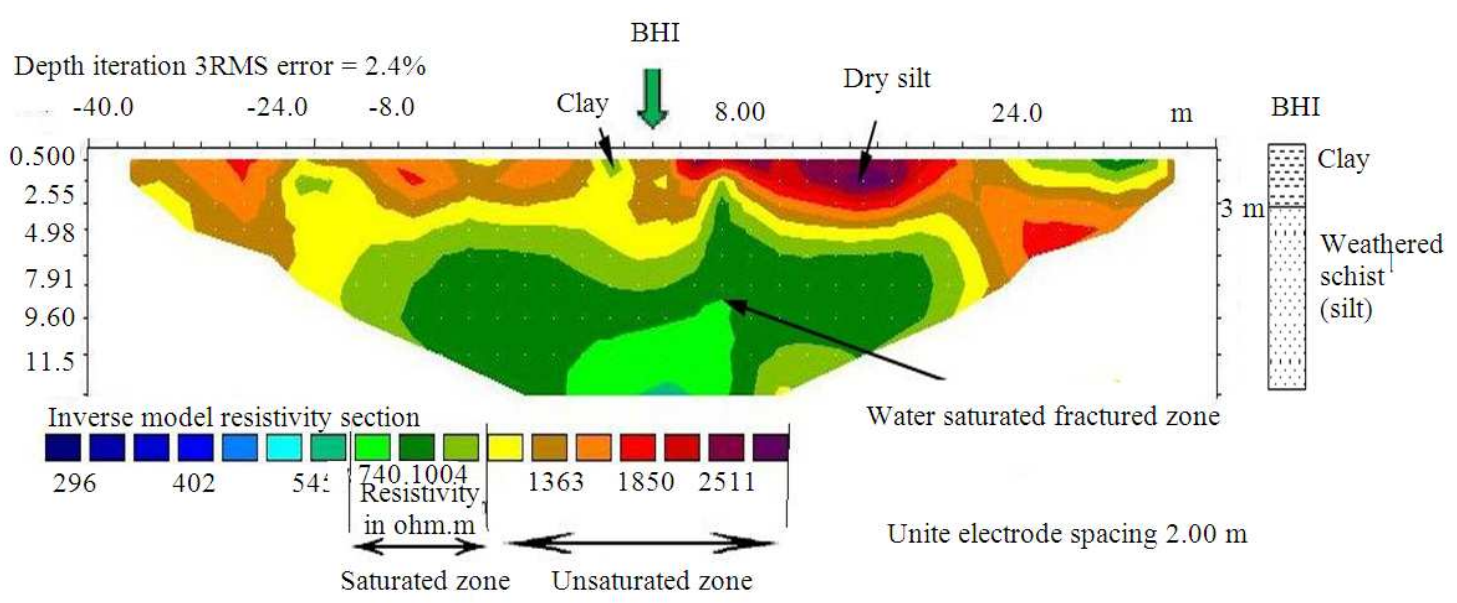

Fig. 5: Resistivity image at BH1 (Electrode spacing $2 \mathrm{~m}$ )

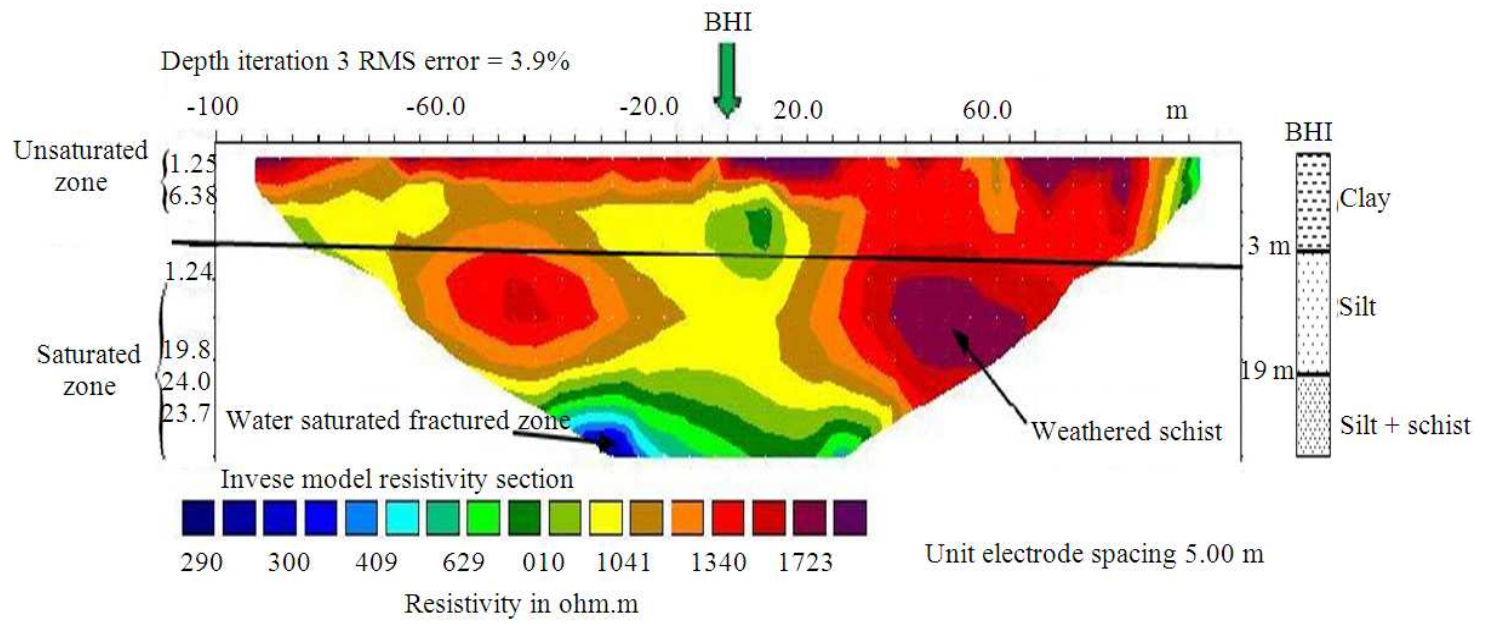

Fig. 6: Resistivity image at BH1 (Electrode spacing 5m)

The subsurface resistivity distribution of the area below BH1 is shown in Fig. 5 and 6 . The resistivity images show the subsurface layered material varies from 290$2500 \Omega-m$ with depth of penetration from $12-27 \mathrm{~m}$.

\section{DISCUSSION}

The 2-D seismic sections with $2 \mathrm{~m}$ geophone spacing indicate three seismic layers. The first layer has seismic velocity ranges from 450-900 m $\mathrm{sec}^{-1}$ with thickness around $6 \mathrm{~m}$; it is associated with top soil that is completely weathered layer. The second layer has a velocity around $1000-1600 \mathrm{~m} \mathrm{sec}^{-1}$ and thickness about $2.5 \mathrm{~m}$ and this is associated with weathered schist. Whereas the third layer has velocity around 1600-2000 m sec-1 and thickness of $2.5 \mathrm{~m}$ and this layer is considered as less weathered schist b. The 2D seismic section for $5 \mathrm{~m}$ geophone spacing indicates four seismic layers. The top three layers are similar to those obtained for the first seismic line in term of their velocity, thickness and types of material, because these two lines are coincident. It gives deeper information than the first line, so that from this line we get an additional layer that is the fourth layer. This layer occurs at depth from $22-33 \mathrm{~m}$ below surface and has velocity around $2000-3000 \mathrm{~m} \mathrm{sec}^{-1}$.

The resistivity image for $2 \mathrm{~m}$ electrode spacing Fig. 5 shows that the unsaturated top soil layer has medium to high resistivity (1100-2600 $\Omega \mathrm{m}$ ) with thickness about $4 \mathrm{~m}$. The large variation of the resistivity values suggests that the soil materials are not homogenous. At 96 
resistivity (750-1100 $\Omega-m)$. Figure 6 shows the resistivity image for $5 \mathrm{~m}$ electrode spacing which gives $28 \mathrm{~m}$ depth of penetration. The unsaturated layer comprise of top soil comprises of clay and silt. While at depth from $20-28 \mathrm{~m}$, it is a water saturated zone which has low resistivity. A high resistivity zones (1723-1900 $\Omega$ $\mathrm{m})$ observed in the image is interpreted as weathered schist Fig. 6. The large variation of resistivity for the unsaturated layer shows that the top soil is not homogenous.

\section{CONCLUSION}

Interpretation of the resistivity and the seismic refraction data have been successfully used to determine the thickness of residual soil layer and depth of bedrock in the study area. The thickness of residual soil obtained by seismic refraction survey appears to agree very well with the borehole data. The borehole data also shows depth of bedrock around $10 \mathrm{~m}$ with Nspt value equal to 50. This corresponds to high velocity layer $\left(>1600 \mathrm{~m} \mathrm{sec}^{-1}\right)$ an indicated in the interpreted of seismic section. The bedrock indicates relatively high resistivity value $(>1000 \Omega-\mathrm{m})$ the occurrence of law resistivity zone within the bedrock suggest that it probably associated with fractured zone. The final output of the integrated interpretation of the resistivity and seismic refraction data along profiles helped us identify the change in the thickness of the subsurface material.

\section{ACKNOWLEDGMENT}

Funding for this research was provided by the ministry of higher education of Malaysia (MOHE), under the FRGS Grant NO.UKM-ST-07-FRGS0022-2010.

\section{REFERENCES}

Barker, R.D., 1981. The offset system of electrical resistivity sounding and its use with a multicore cable. Geophys. Prospect., 29: 128-143. DOI: 10.1111/j.1365-2478.1981.tb01015.x

Griffiths, D.H. and R.D. Barker, 1993. Twodimensional resistivity imaging and modelling in areas of complex geology. J. Applied Geophys., 29: 211-226. DOI: 10.1016/0926-9851(93)90005-J

Loke, M.H. and R.D. Barker, 1995. Least-squares deconvolution of apparent resistivity pseudosections. Geophysics, 60: 1682-1690. Geophysics, 61: 621-621. DOI: 10.1190/1.1443900

Loke, M.H., I. Acworth and T. Dahlin, 2003. A comparison of smooth and blocky inversion methods in 2D electrical imaging surveys. Exp. Geophys., 34: 182-187. DOI: 10.1071/EG03182

Telford, W.M., L.P. Geldart and R.E. Sheriff, 1990. Applied Geophysics. 2nd Edn., Cambridge University Press, Cambridge, ISBN-10: 0521326931, pp: 770. 